\title{
Tourisme et « coronisation » au Mali : des visiteurs à l'abri des rumeurs
}

Tourism and "Coronization" in Mali: Visitors Safe From Rumors

Anne Doquet

\section{OpenEdition}

Journals

Édition électronique

URL : https://journals.openedition.org/tourisme/3854

DOI : $10.4000 /$ tourisme.3854

ISSN : 2492-7503

Éditeur

Association Mondes du tourisme

Référence électronique

Anne Doquet, «Tourisme et « coronisation » au Mali : des visiteurs à l'abri des rumeurs », Mondes du Tourisme [En ligne], 20 | 2021, mis en ligne le 15 décembre 2021, consulté le 17 décembre 2021. URL http://journals.openedition.org/tourisme/3854 ; DOI : https://doi.org/10.4000/tourisme.3854

Ce document a été généré automatiquement le 17 décembre 2021.



Mondes du tourisme est mis à disposition selon les termes de la licence Creative Commons Attribution - Pas d'Utilisation Commerciale - Pas de Modification 4.0 International. 


\section{Tourisme et « coronisation » au Mali : des visiteurs à l'abri des rumeurs}

Tourism and "Coronization" in Mali: Visitors Safe From Rumors

Anne Doquet

1 En octobre 2020, je me rends à Bamako pour une mission scientifique de courte durée. Depuis plusieurs mois, les cas officiels de Covid-19 se font rares (une deuxième vague arrivera au Mali le mois suivant) et, de l'intérieur, le pays semble totalement hermétique au virus. Aucune mesure protectrice n'est constatable dans la capitale. De mon côté, j'ai été testée positive un mois auparavant. Très vite, de nombreuses conversations s'engagent autour de cette expérience ${ }^{1}$. Décrivant les symptômes de ce Covid léger, je me rends vite compte de l'étonnement de la plupart de mes interlocuteurs qui, me connaissant de longue date, ne remettent pas en question mon récit. Leur réaction se résume à cette phrase: "Donc, ça existe!». S'ensuivent de longues discussions qui me font comprendre l'ampleur des rumeurs circulant autour du virus. Y domine l'idée d'une invention de la maladie par les "Blancs", dans le but d'imposer des mesures conduisant le pays à l'effondrement afin de mieux le contrôler. Au cours de ce même séjour, une manifestation se déroule à Bamako, en réaction aux propos tenus par Emmanuel Macron sur les caricatures de Mahomet. La contestation des positions de la France s'étend alors un peu plus, alors que le départ des troupes françaises du territoire malien a déjà été réclamé lors de plusieurs rassemblements. En quelques jours et au fil des conversations, je peux mesurer l'étroitesse des liens établis entre le Covid et les accusations de néocolonialisme dont la France fait l'objet.

2 Les prévisions catastrophistes émises par la communauté internationale au sujet des potentiels ravages du coronavirus en Afrique ont été démenties par les chiffres. Passés la crainte du pire et l'anniversaire du premier cas connu sur le sol du continent, on s'est rendu compte qu'à l'exception de ses extrémités Nord-Sud, l'Afrique s'en était plutôt bien sortie, avec un taux estimé à $4 \%$ du nombre de victimes total de l'épidémie pour un nombre d'habitants représentant $15 \%$ de la population mondiale ${ }^{2}$. Le continent n'a pour autant pas échappé à la crise économique mondiale et à l'effondrement général du 
secteur touristique, avec une chute de $70 \%$ des arrivées en 2020 alors que ces dernières avaient augmenté de $6 \%$ en $2019^{3}$. Comme partout dans le monde, l'apparition du virus a donc rimé, en Afrique, avec l'extinction du tourisme. Au Mali pourtant, les touristes avaient déserté le terrain depuis une dizaine d'années déjà lorsque le premier cas d'infection a été déclaré le 24 mars 2020. Une série d'évènements - enlèvement en 2009 de plusieurs Occidentaux dans le nord du pays, traçage de zones rouges par les ministères des affaires étrangères européens, occupation du Nord par des groupes rebelles touaregs puis par des mouvements djihadistes-, conjugués à une profonde crise politique nationale avait en effet progressivement découragé l'ensemble des visiteurs cherchant au Mali une destination paisible et authentique. Pourtant, passée de 98000 en 2000 à 250000 en $2007^{4}$, la courbe des arrivées touristiques sur le sol malien augurait d'une croissance exponentielle du secteur, sur lequel l'État misait beaucoup au tournant du millénaire. En 2010, soit au moment où la situation commençait à se dégrader, le Mali constituait la deuxième destination d'Afrique de l'Ouest, derrière le Sénégal, en termes de nombre d'arrivées touristiques et le secteur représentait la troisième entrée de devises du pays, après l'or et le coton. Huit ans après, le nombre d'arrivées touristiques peinait à dépasser 200 000, tandis que selon les statistiques de la direction nationale du Tourisme et de l'Hôtellerie ${ }^{5}, 12,7 \%$ seulement des étrangers entrant sur le territoire pour une durée inférieure à un an déclaraient voyager au motif de « vacances-loisirs ». Seul le tourisme d'affaires (rubrique "voyages d'affaires et de congrès ») s'était maintenu à des taux honorables ( $28,6 \%$ en 2019) malgré son évolution en dents de scie, mais il relevait de séjours brefs et concentrés exclusivement dans la capitale. Avec la pandémie, la fermeture des frontières internationales a naturellement joué sur la venue des touristes d'affaires, derniers visiteurs du pays. Mais ce n'est pas tant le lien direct entre l'apparition du virus et la baisse des arrivées touristiques à Bamako en 2020 qui nous intéresse ici, que celui qui permet d'analyser conjointement le tourisme de loisir, en extinction depuis une dizaine d'années, et l'arrivée récente de la pandémie. Il s'agira en effet d'éclairer un point de rencontre de deux phénomènes décalés dans le temps, mais liés par les lourds griefs envers l'ancienne puissance coloniale qu'ils ont occasionnés. Aussi, tandis que dans de nombreuses régions du monde, le tourisme est de plus en plus frappé d'accusations de néocolonialisme, ces dernières sont au Mali tournées vers la France pour ses interventions militaires comme pour sa lutte contre la pandémie, sans que les touristes ne soient ciblés. Au sein des discours dénonciateurs de l'ancienne tutelle coloniale, le tourisme est paradoxalement perçu comme victime du système dont il est issu.

\section{Tourisme et oscillations des points de vue sur la France}

3 À l'instar de toutes les relations entre des pays anciennement colonisés et les anciennes puissances coloniales, les relations du Mali et de la France ont été fluctuantes et tissées d'ambivalence. Si, avec l'intervention militaire française, l'amitié franco-malienne a atteint son pic en 2013, l'ancienne tutelle avait, quelques années auparavant, fait l'objet de sévères reproches de la part de plusieurs personnalités politiques maliennes. En 2009, en effet, l'enlèvement de plusieurs individus occidentaux avait renforcé les craintes autour de la présence d'une branche d'Al-Qaïda dans le nord du pays et avait conduit la France, jugeant le Mali incapable de contrôler ses frontières, à colorier en 
rouge la partie nord du pays, dès lors "formellement déconseillée " aux étrangers. Tandis que d'autres pays occidentaux s'alignaient sur les positions de l'Hexagone, l'office malien du tourisme et de l'hôtellerie (OMATHO) s'offusquait des « campagnes d'intoxication médiatiques lancées par le ministère français des Affaires [étrangères] » et répliquait par un démenti immédiat, affirmant que les touristes pouvaient «se rendre au Nord-Mali quand ils veulent et où ils veulent» et qu'il y avait "plus de sécurité au Mali qu'à Paris $»^{6}$. Le travail de Marta Amico a montré comment cette riposte aux positions alarmistes de la France s'est concrétisée, entre décembre 2009 et janvier 2010, par la centralisation à Tombouctou d'un ensemble d'événements culturels nationaux ${ }^{7}$, mais aussi par l'organisation du célèbre Festival au désert malgré le coloriage en rouge de la zone (Amico, 2020). Tandis que le ministre du Tourisme dénonçait la chute des activités touristiques consécutive à la campagne de désinformation internationale et garantissait aux visiteurs un séjour et des déplacements sans risque, l'organisation du festival récusait les allégations françaises dans une stratégie efficace : en 2010, il accueillait 80 journalistes, mais aussi et surtout 600 touristes, venus principalement d'Europe, d'Australie et des États-Unis. Si la programmation était exceptionnelle (groupes touaregs internationalement connus et stars de la musique malienne) et le déploiement militaire et sécuritaire à la hauteur afin de faire face aux menaces d'enlèvement, les organisateurs du festival estimaient cette réussite " miraculeuse » (Amico, 2020, p. 166) et il était alors remarquable de voir de nombreux touristes adopter des positions très militantes pour soutenir la cause des nordistes. Certains, qui avaient prévu de ne voyager que dans la partie du pays coloriée en orange, s'étaient laissés convaincre par leur guide qu'il fallait se rendre au festival pour sauver le Nord de l'intoxication médiatique et politique internationale ${ }^{8}$. Et les Français les plus réfractaires aux actions du président de l'époque, Nicolas Sarkozy, s'en donnaient à cœur joie, aux micros des journalistes, en attaquant la politique française néocoloniale. En épousant les causes maliennes, les touristes français ont finalement formé un groupe d'individus qui, malgré leur nationalité, allait échapper aux disqualifications frappant l'Hexagone. Aussi, alors qu'avec l'instauration de la zone rouge, deux des quotidiens les plus lus au Mali, l'Essor et l'Indépendant, parlaient tour à tour d'" agression culturelle étrangère " et de «bruits des imposteurs néocolonialistes » (Amico, 2000, p.175), les touristes du Nord-Mali apparaissaient inversement comme des résistants au néocolonialisme.

4 Le lien entre cette forme de domination et le tourisme a été largement analysé (Hall et Tucker, 2004; Tucker et Akama, 2009). À l'aube des années 1980, une poignée de chercheurs français l'interrogeait sur le terrain africain en ces termes: «Panacée ou nouvelle traite?», en penchant clairement pour la seconde proposition (Boutillier et al., 1978). L'analyse des relations entre les touristes et les guides maliens a également décrit la rencontre touristique en tant qu'héritière de situations de violence et de domination coloniales (Doquet, 2009). Mais, alors que le touriste a longtemps porté l'encombrant héritage de ces relations, il semble s'en être dégagé au moment où l'imposition d'une zone rouge privait le Mali de ses visiteurs, français pour la plupart. Tandis que l'État français établissait une frontière entre les espaces fréquentables et les zones interdites pour ses ressortissants, une autre frontière semblait en retour séparer ces derniers en deux groupes : les acteurs du secteur touristique voyaient, d'un côté, la France néocoloniale avec ses corps militaires, diplomatiques et expatriés, et, de l'autre, les touristes qui n'étaient pas identifiés aux actions gouvernementales et semblaient même en être les pourfendeurs 9 . Encore présents en 2010 malgré les consignes, ces 
visiteurs bienvenus au Mali déserteront pourtant d'abord le Nord, puis l'ensemble du territoire malien, sur lequel s'installera progressivement le chaos. L'année 2012 restera sans aucun doute l'une des pires années pour le pays. Dès le début de l'année, la rébellion touarègue prend le contrôle d'une large partie du nord du pays qui, quelques mois plus tard, tombe aux mains des mouvements islamistes. Le Sud, quant à lui, traverse une année politique plus que mouvementée : coup d'état militaire en mars, agression violente du président de la république par intérim en mai, démission du premier ministre sous la contrainte des militaires putschistes en décembre. Noyée dans sa propre instabilité, la capitale se montre incapable, à la fois politiquement et militairement, de venir au secours du Nord. Début 2013, l'offensive en direction du sud de combattants de mouvements islamistes déclenche l'intervention militaire française et le lancement de l'opération Serval, qui fait apparaitre la France comme le pays sauveur du Mali. En deux semaines, les forces franco-maliennes reprennent les villes du Nord occupées et François Hollande est accueilli en libérateur, le 2 février à Tombouctou, par une foule en liesse. Il dira de cet évènement qu'il a représenté le plus beau jour de sa carrière politique. L'année 2013 est donc marquée par des relations au beau fixe entre le Mali et l'ancienne puissance coloniale. Le lancement de l'opération Barkhane ${ }^{10}$, en tout début d'année suivante, est reçu avec le même enthousiasme, avant que la question de sa durabilité et ses zones d'ombre n'assombrissent les relations entre les deux pays. Sans détailler l'enlisement progressif de la situation, nous pouvons la résumer en quelques points : retour au Nord du MNLA ${ }^{11}$, menaces permanentes sur l'intégrité du territoire, accroissement de la perte d'autorité de l'État, redéploiement des mouvements islamistes, insécurité galopante, attaques et meurtres au Nord mais aussi au centre du pays. Les espoirs de recouvrement de paix et d'intégration territoriale ont alors dégringolé et de cette dégradation flagrante de la situation ont germé puis mûri des rumeurs et des soupçons sur le rôle joué par la France dans ce chaos. Dans les médias comme dans les réseaux sociaux, l'idée d'un agenda caché de l'ancienne puissance coloniale va finir par dominer, en alternant entre "deux récits distincts mais liés » (Tull, 2021, p. 159) : celui d'un soutien de la France aux séparatistes touaregs et celui d'une tentative d'accaparement des richesses du sol du Nord du pays. Loin de se limiter à la rue, ces discours sont tenus par de hauts fonctionnaires de l'État ou encore par d'influentes personnalités du pays. En novembre 2019, le célèbre chanteur Salif Keïta accuse par exemple la France d'être la main occulte du terrorisme et la responsable du décès de centaines de Maliens innocents. En août 2020, le très populaire imam Mahamoud Dicko taxe la France d'ingérence, prétendant qu'elle est derrière les décisions du président de la république, et lui demande de respecter les Maliens. Ces accusations, en apparence divergentes, sont en fait liées. Elles ont tout d'abord en commun de ne pas émaner de fonctionnaires soupçonnables de se dédouaner de leur propre responsabilité mais aussi d'être portées par des personnalités très écoutées par les populations. Leurs cibles s'inscrivent, d'autre part, dans le récit cohérent d'une France conspiratrice associée aux terroristes et d'hommes politiques influents faisant le jeu de la France pour percevoir les bénéfices d'une situation stratégiquement attisée. Aux manifestations réclamant en 2019 et 2020 le départ des forces armées internationales, et de la France en particulier, ont succédé plusieurs sorties massives des populations dans les rues qui ont abouti au renversement du président Ibrahim Boubacar Keita. L'État était ainsi apparu, au fil du temps, comme le co-responsable de la perte de sa souveraineté, en association avec l'ex-colonisateur revenu prendre ses droits sur le territoire malien. Durant toutes ces années de 
dégradation de la situation politico-sécuritaire, l'arrivée des visiteurs au Mali a été progressivement freinée avant d'être totalement stoppée, sauf pour le tourisme d'affaires cantonné à Bamako. La presse malienne s'est alors largement étendue sur les conséquences dramatiques, à l'échelle nationale, de l'effondrement du secteur. Même si, depuis quelques années, de nouvelles pistes sont envisagées pour le redynamiser, comme le développement du tourisme local ou l'ouverture au marché asiatique ${ }^{12}$, c'est dans des termes très nostalgiques que les médias et les acteurs politiques rappellent l'âge d'or du tourisme malien, tandis que les guides se souviennent des «Toubabs qui s'intéressaient à nous, pas à l'or ou au pétrole $»^{13}$ - comme si l'absence des touristes les avait préservés de la fluctuation des sentiments envers la France, alternant entre rancœurs, ovations, méfiances et hostilités. L'arrivée, en 2020, de la Covid-19 aurait pu changer la donne. En effet, la propagation de la pandémie a tendu les rapports NordSud au niveau mondial, tout comme les relations entre la France et ses anciennes colonies au niveau du continent. Et, tandis que les rumeurs les plus complotistes ont circulé sur le rôle joué par les puissances occidentales dans la diffusion du virus en Afrique, les touristes occidentaux sont apparus à maints endroits du globe comme de dangereux vecteurs de contamination. Dans de nombreux pays, en effet, tourisme et coronavirus se sont retrouvés conjointement pris dans une grille de lecture néocoloniale.

\section{La pandémie sans les touristes}

5 Même si les statistiques laissent penser à une sous-évaluation des cas réels, l'Afrique est restée, à l'encontre des prévisions alarmistes des experts internationaux, relativement épargnée par la pandémie. La diffusion du virus y a néanmoins accru la pauvreté et les inégalités sociales de manière drastique. Parmi les mesures de restriction internationales prises par les gouvernements africains pour enrayer la pandémie, la fermeture des aéroports, voire des frontières terrestres, a déréglé les marchés internationaux, mais aussi littéralement paralysé le secteur touristique. Dans cette configuration, à la fois inédite et mondialisée, le tourisme et le virus se sont côtoyés durant plusieurs mois et les touristes ont souvent été jugés coupables de contamination, à l'instar du jeune français inculpé par la justice sud-africaine en mars 2020 pour «tentative de meurtre» après avoir été accusé de propager le Covid-19 ${ }^{14}$. Dans le cadre d'un tourisme Nord-Sud, et plus particulièrement sur les territoires anciennement colonisés, les accusations de contamination par les touristes se sont rapidement doublées du soupçon d'une volonté occidentale de décimer une partie des populations africaines, notamment par le biais des vaccins. Ces suspicions n'ont rien de propre au Mali, ni à l'Afrique. Au Sénégal ou en Guinée, les mises en scène de décès d'enfants suite à une campagne de vaccination ont alimenté les infox (Desclaux, 2021). Celles-ci se nourrissent par ailleurs d'interprétations véhiculées au cours d'épidémies antérieures : tandis que différents travaux sur la prévention du VIH ont montré à quel point la réception des messages préventifs dépendait des représentations sous-jacentes des maladies préexistantes et de leur transmission sociale (Desclaux, 1997), les imaginaires déployés autour du sida sont réactivés par l'apparition de la Covid: imputations de contagiosité à l'Autre, racisme, peurs, rumeurs (Pezeril, 2020). Parallèlement, l'apparition d'une épidémie de cette ampleur engendre une période de 
crise mondialisée qui réveille l'adhésion à des thèses conspirationnistes risquant d'impacter fortement la santé publique (Poupart et Bouscail, 2021).

6 Si le succès des croyances conspiratrices circulant sur les réseaux sociaux en Afrique de l'Ouest n'a donc rien d'étonnant, il doit être compris dans la suite d'une série d'accusations de néocolonialisme (contre la France en particulier), de revendications d'une réelle indépendance (monétaire notamment) et d'une volonté de mettre fin à la "Françafrique ", de plus en plus ouvertement dénoncée. La rue s'est elle-même emparée de ces doléances dans plusieurs pays, que ce soit dans les manifestations antiBarkhane à Bamako ou celles du mouvement « France dégage » à Dakar. C'est donc au sein d'un processus de rupture largement entamé qu'est apparu la Covid, une maladie venue du Nord dont la réalité a été, dans un premier temps, mise en doute et qui était, au mieux, considérée comme une « maladie des Blancs » que les Africains ne pourraient pas contracter. Plusieurs études scientifiques ont émis des hypothèses pour comprendre la résistance du continent africain à la propagation du virus, qui s'expliquerait notamment par la pyramide des âges et des capacités réactives consécutives aux expériences épidémiques antérieures (Eboko et Schlimmer, 2020). Quoi qu'il en soit, la Covid est arrivée tardivement sur le sol malien et le fait que les deux premiers cas avérés, qui datent de mars 2020, concernent des binationaux vivant et mangeant à l'européenne a pu corroborer l'idée que la maladie n'affecterait pas les corps des locaux. Les statistiques sont, de fait, restées très faibles durant des mois : la première vague de mai-juin, au cours de laquelle ont officiellement été recensés 116 décès, a ensuite fait place à une nette accalmie de plusieurs mois, de sorte que la négation de l'existence du virus a pris le dessus, avec la conviction que l'Occident aurait inventé une maladie pour semer la terreur et imposer aux pays africains des lois restrictives en vue de mieux exploiter leurs ressources et leurs marchés économiques. Il faut dire que l'économie malienne, déjà mal en point depuis plusieurs années, est tombée très bas. Dès avril 2020, le FMI estimait ainsi l'impact de la Covid-19 au Mali : chute de la croissance en dessous d'1 \%, augmentation du chômage et de la pauvreté ${ }^{15}$. Cette aggravation de la crise économique n'a fait qu'exacerber les aigreurs et les mécontentements, tandis qu'une deuxième vague pointait au mois de novembre. La multiplication des cas a alors modéré le déni de l'existence du virus au profit de l'émergence de la catégorie de « maladie de Blancs » qui, dans des certains pays, a réuni « les Blancs et les Blanchis (Africains vivant à l'extérieur)» (Bonono-Momnougui, 2020, p. 26). Au Mali, comme dans d'autres pays d'Afrique de l'Ouest, a circulé l'idée d'une maladie frappant les Blancs selon la volonté divine et par un juste retour des choses après que les plus grands fléaux se sont systématiquement abattus en terre africaine. Néanmoins, face au nombre croissant de cas positifs, c'est l'hypothèse d'une contamination stratégique des populations par la France qui a fini par s'installer. La propagation préméditée du virus en Afrique était alors interprétée comme une volonté occidentale, et française en particulier, de réduire la démographie de l'Afrique en exterminant une part importante de sa population, notamment sur la base de vaccins contaminés (Desclaux, 2021). Suite aux propos tenus à la télévision par deux médecins français, une autre version des fins réelles de la vaccination en Afrique a largement circulé, affirmant que des essais thérapeutiques y seraient réalisés à l'insu des populations. Aussi, quelle que soit l'énormité des rumeurs, leurs effets concrets témoignent d'un degré d'adhésion intense à leur contenu. Au Mali, une enquête menée dans le centre de santé communautaire et universitaire de Konobougou a analysé la chute respective, en avril et mai 2020 , de $22 \%$ et de $41 \%$ de la proportion d'enfants 
complètement vaccinés contre la rougeole. L'étude a montré que les abandons des séances de vaccination tenaient pour $89,4 \%$ à la crainte que les enfants soient victimes, à l'insu de leurs parents, d'un test d'essai pour le Covid-19 (Coulibaly et al., 2020). Largement propagées par les réseaux sociaux, les rumeurs autour du virus ont eu d'autant plus d'efficacité qu'aux soupçons de malveillance occidentale se sont peu à peu mêlés des doutes sur les intentions des acteurs politiques locaux. Au Mali et dans plusieurs pays frontaliers aux situations politiques instables, l'idée d'une complicité des régimes en place s'est en effet progressivement conjuguée à celle de manœuvres stratégiques de l'ancienne puissance coloniale: les gouvernants auraient monté de toute pièce la propagation du virus pour capter, à leur propre compte, les dons de l'aide internationale. Ils se seraient alliés aux projets démoniaques de l'Occident dans le simple but de «bouffer ». En Côte d'Ivoire, le virus a ainsi pu apparaître comme une " construction idéologique » destinée à bénéficier des soutiens financiers extérieurs (Kassoum et Memon, 2020, p. 39). Au Mali, comme au Burkina Faso, était soulignée l'étrangeté du fait que ni les malades, ni les corps des défunts n'étaient jamais visibles. Des hommes politiques étaient soupçonnés de feindre une contamination pour persuader les populations de l'existence du virus ${ }^{16}$. On suspectait les autorités sanitaires de manipuler les chiffres annoncés par les communiqués officiels quotidiens (Togo, 2020). À Bamako, les mesures de restriction prises par la présidence (fermeture des écoles, des bars, des restaurants et de certains commerces en décembre 2020, déclaration d'un état d'alerte sanitaire de six mois et d'un état d'urgence de dix jours) sont apparues comme de pures stratégies coercitives, dans une période où le gouvernement était de plus en plus décrié. Les défiances envers ces restrictions étaient bien visibles dans la capitale, où ni le port du masque, ni les distanciations physiques n'étaient respectés, pas même dans les cérémonies de mariage ou les prières collectives (Togo, 2020). L'incohérence de certaines mesures, comme la non-fermeture des mosquées ou le maintien des élections législatives le 19 mars et le 29 avril, n'a par ailleurs fait qu'exacerber les doutes.

7 En comparant les discours portés au Mali sur la guerre au nord du pays et sur le coronavirus, il est finalement facile d'observer un processus similaire de propagation des rumeurs. Dans un premier temps, la réalité des fléaux qui s'abattent à une décennie d'écart sur le pays - le djihadisme d'une part, le coronavirus de l'autre - est niée. Des thèses conspiratrices viennent alors dénoncer l'intervention et les soutiens occidentaux, qu'ils soient militaires, financiers ou sanitaires, ainsi que la mainmise de la France sur le Mali, autrement dit ses pratiques néocoloniales. Si différents pays européens sont associés à la coopération de l'Hexagone, la France reste la coupable présumée de toutes les malversations, en raison d'une part de son passé colonial et d'autre part de son poids dans les décisions d'ordre militaire. Progressivement, les gouvernants sont par suite soupçonnés de sacrifier leur population dans des buts intéressés et en complicité avec l'ancienne puissance dominatrice. Les touristes, tout français qu'ils soient, semblent néanmoins avoir été épargnés par ces rumeurs. Considérés comme des résistants au moment où la France coloriait en rouge la partie nord du pays, ils ont ensuite brillé par leur absence et alimenté des discours nostalgiques au Mali, tandis qu'ils faisaient l'objet d'attaques et d'accusations dans d'autres pays. Dix ans après le début de l'effondrement du pays dans une crise profonde, l'arrivée de la pandémie a renforcé les accusations de néocolonialisme et les remises en question des rapports de force Nord-Sud aux quatre coins du globe. Mais, tandis qu'à maints endroits les visiteurs étrangers ont été perçus comme des agents 
contaminateurs, leur absence au Mali les a lavés de toute accusation de malveillance. Enlisé dans un drame sans fin, le pays n'a retenu que le versant positif du tourisme. Au fil des années et du désespoir, la mémoire des tensions, des relations inégalitaires et/ou racistes s'est amenuisée au profit de souvenirs des moments de générosité, de confidence ou de partage, que l'insécurité et l'appauvrissement considérable des régions les plus prisées des visiteurs ont contribué à magnifier. Le poids économique que représentait le secteur touristique est de même régulièrement regretté, que ce soit par les médias ou par les acteurs politico-économiques impliqués dans le secteur.

Si, en Afrique, la propagation d'un virus venu du Nord a nourri des revendications de rupture avec les anciens pays colonisateurs, elle s'est, au Mali, inscrite dans une accumulation de doutes sur les intentions réelles de la présence militaire de la France au nord du pays et d'accusations de plus en plus sévères à son encontre sur les réseaux sociaux. Le fait que les touristes aient été exemptés du sentiment anti-français au Mali relève peut-être d'une exception. Il est ainsi remarquable qu'au Cameroun, où a circulé la thèse des "mules " selon laquelle des "vagues de voyageurs venus de la France étaient des envoyés "chargés de Covid-19" aux fins de l'élimination de nombreux Camerounais et même des autorités... » (Bonono-Momnougui, 2020, p. 29), la France soit soupçonnée par les populations de connivence avec les opposants et de complicité avec Boko-Haram, là encore à des fins néocolonialistes. Dans le prolongement du lien entre tourisme et postcolonialisme, établi de longue date, celui entre le néocolonialisme et l'apparition et la propagation de la Covid-19 a explosé dans les réseaux sociaux. Les néologismes "coronisation" et "coroniser" ont ainsi largement circulé, au Mali comme dans d'autres pays d'Afrique de l'Ouest. Le 4 mars 2020, le journal sénégalais L'évidence faisait sa une avec ce titre : «La France "coronise" le Sénégal ». Le sous-titre était on ne peut plus explicite: "Traite négrière, colonisation économique, colonisation épidémiologique ». À la lumière de la gestion catastrophique de la pandémie en Europe et en France particulièrement, il est évident que l'autorité morale des pays occidentaux sur les pays africains a considérablement chuté (Diop, 2020) et que la pandémie a marqué une étape dans l'évolution des rapports de force entre l'Afrique et l'Occident. Le tourisme post-Covid en gardera-t-il les traces? Tandis que le secteur, au point mort, tente de repenser ses pratiques et envisage de se tourner vers des formes de voyage et de rencontre plus respectueuses et plus éthiques, "corona " serait devenu dans plusieurs pays d'Afrique le terme employé pour désigner un Occidental ${ }^{17}$. Quelle que soit la durée de vie de cette appellation, gageons qu'au moment de la reprise des activités touristiques au Mali, les visiteurs français en seront épargnés.

\section{BIBLIOGRAPHIE}

Marta AMICO, La fabrique d'une musique touarègue, Karthala, 2020.

Cécile Renée Bonono-MOMNOUGUI, « Grande palabre croisée de la pandémie : une Covid-19 en cache d'autres. Élaborations socio-culturelles », dans Sabine Patricia Moungou Mbenda et Viviane 
Ondoua Biwole, Épidémiologie de l'économie et confinement de l'organisation Covid-19, Presses Universitaires de Yaoundé, 2020, p. 21-34

Jean-Louis BOUTILLIER, Jean COPANS, Michèle FIELLoux, Suzanne LALLEMAND et Jean-Louis ORMIÈrES, Le tourisme en Afrique de l'Ouest. Panacée ou nouvelle traite ?, Maspero, 1978.


« Impact des rumeurs d'essai de vaccin contre la Covid-19 sur le PEV : comment rehausser ses indicateurs au CSCom-Universitaire de Konobougou, Mali ? ", Jaccr Africa, vol. 4, n 3, 2020.

Alice DESCLAUX, «Dix ans de recherches en sciences sociales sur le sida au Burkina Faso. Éléments pour la prévention ", Cahiers d'études et de recherches francophones/santé, vol. 7, n 2, p. 127-134, 1997.

Alice DESCLAuX, « Covid-19 : en Afrique de l'Ouest, le vaccin n'est pas le nouveau "magic bullet" ", Vih.org, 2 février 2021 [https://vih.org/20210202/la-mondialisation-des-informations-et-lafabrique-des-opinions-sur-les-traitements-du-covid-en-afrique/?fbclid=IwAR0BWZs_hlm5UmHk3omVM4N4S1GaRQoWm6Le2FYjRVDZ6AGI4cRTReLSP0]

Boubacar Boris DIoP, « Après la pandémie, le réveil de l'Afrique? », Le Monde diplomatique, juillet 2020.

Anne DOQUET, « Guides, guidons et guitares. Authenticité et guides touristiques au Mali », Cahiers d'études africaines, vol. 193-194, n 1-2, p. 73-94, 2009.

Fred Евоко et Sina SCHLIMмER, « Covid-19 : l'Afrique face à une crise mondiale », Politique étrangère, $\mathrm{n}^{\circ}$ 4, p. 123-134, 2020 [https://doi.org/10.3917/pe.204.0123].

Michael C. HALL et Hazel TUCKER (dir.), Tourism and Postcolonialism: Contested Discourses, Identities and Representations, Routledge, 2004.

Charlotte PEZERIL, « Du Sida au Covid 19. Les leçons de la lutte contre le VIH », La vie des idées, septembre 2020 [https://laviedesidees.fr/Du-Sida-au Covid-19.html].

Florent POUPART et Manon BOUSCAIL, « Enjeux psychiques et psychopathologiques des croyances conspirationnistes : de la crise sanitaire du Covid-19 à la crise ", Annales médio-psychologiques, $\mathrm{n}^{\circ}$ 179, p. 311-316, 2021 [https://doi.org/10.1016/j.amp.2021.03.004].

Kassoum TRAORE et Memon FOFANA, «Causes et expressions de la propagation rapide du nouveau coronavirus "Covid-19" en Côte d'Ivoire ", European Journal of Social Science Studies, vol. 5, n 2, p. 32-52, 2020 [https://doi.org/10.5281/zenodo.3784860].

Souabou TOGO, « La communication de crise. Les questions principales à traiter, cas du Mali face au Covid-19 », Revue Économie, Gestion et Société, vol. 1, n 27 (numéro spécial : Ouvrage collectif sur la crise pandémique de Coronavirus), p. 90-101, 2020.

Hazel TUCKER et John AKAMA, « Tourism as Postcolonialism », dans Tazim Jamal et Mike Robinson (dir.), The SAGE handbook of tourism studies, SAGE, 2009, p. 504-520.

Denis M. TULL, « Contester la France : rumeurs, intervention et politique de vérité au Mali », Critique internationale, $\mathrm{n}^{\circ}$ 90, p. 151-171, 2021.

\section{NOTES}

1. Les propos de mes interlocuteurs relatés dans cet article relèvent de ces conversations spontanées. 
2. En Afrique, l'ampleur de l'épidémie de Covid-19 reste une grande inconnue, Le Monde Afrique, 14 février 2021 : https://www.lemonde.fr/afrique/article/2021/02/14/en-afrique-l-ampleur-de-lepidemie-de-covid-19-reste-une-grande-inconnue_6069904_3212.html

3. Baromètre de l'Organisation mondiale du tourisme (OMT), 2020.

4. Journal Les échos, 12 novembre 2010, dossier « Tourisme malien ».

5. http://tourismemali.simplesite.com/429490030

6. Journal Les échos, 12 novembre 2010, dossier «Tourisme malien » : http://www.jamana.org/ lesechos/articles/2010/novembre/ec_12novembre.html.

7. La rentrée culturelle du ministère de la Culture, la quinzaine touristique de l'assemblée régionale et le lancement de la saison touristique du ministère de l'Artisanat et du Tourisme.

8. Entretiens personnels avec plusieurs touristes français, Bandiagara, décembre 2009.

9. Entretiens menés avec des guides touristiques, des directeurs d'agence de voyages, des hôteliers et des agents du ministère du Tourisme en 2010 et 2011 à Bamako et dans différentes zones coloriées en orange, dans le cadre d'une recherche de long terme sur «tourisme et constructions identitaires " au Mali. Si ce point de vue n'est pas généralisable à l'ensemble des Maliens, il était exprimé très majoritairement dans les cercles d'acteurs du monde touristique qui voyaient leur clientèle s'amoindrir au fil des mois.

10. Serval était une opération militaire française destinée à aider les troupes maliennes. L'opération Barkhane est, elle, menée avec cinq pays de la zone sahélienne.

11. Mouvement national de libération de l'Azawad, mouvement touareg revendiquant l'indépendance du territoire de l'Azawad au nord du Mali.

12. https://www.liberation.fr/planete/2019/05/13/au-mali-quelques-pistes-contre-la-chute-dunombre-de-voyageurs-occidentaux_1726787/

13. Entretien personnel avec un guide touristique, octobre 2020.

14. https://www.lemonde.fr/afrique/article/2020/04/24/afrique-du-sud-un-alsacien-inculpe-detentative-de-meurtre-pour-avoir-repandu-le-coronavirus_6037628_3212.html

15. https://www.voaafrique.com/a/le-fmi-d\%C3\%A9bourse-200-4-millions-de-dollars-pour-lemali-contre-la-pand\%C3\%A9mie/5399503.html

16. Entretiens personnels, Bamako, octobre 2020.

17. https://www.humanite.fr/face-la-pandemie-de-covid-les-dessous-du-miracle-africain-702226

\section{RÉSUMÉS}

Si la Covid-19 a fait chuter l'économie touristique au niveau mondial, elle a plus faiblement impacté le tourisme au Mali, où le secteur s'est effondré, dans un contexte de crise et de guerre, bien avant l'arrivée de la pandémie. Mais là où le tourisme et le coronavirus se sont en réalité peu croisés, ils se rejoignent dans le prolongement des griefs qu'ils ont occasionnés envers l'ancienne puissance coloniale. Au Mali, les accusations de néocolonialisme, ailleurs portées contre le tourisme, frappent la France tout autant pour ses interventions militaires que pour sa lutte contre la pandémie. Dans ces discours dénonciateurs, le tourisme devient paradoxalement victime du système qui l'a engendré.

While Covid-19 globally sent the tourism economy into freefall, it had a smaller impact on tourism in Mali, where the sector collapsed in a context of crisis and war long before the pandemic. But if tourism and the coronavirus have had little to do with each other, they were 
united in the extension of grievances they have caused against the former colonial power. In Mali, the accusations of neo-colonialism, which have been brought against tourism elsewhere, are made against France as much for its military interventions as for its fight against the pandemic. In these denunciatory speeches, tourism paradoxically becomes a victim of the system that created it.

INDEX

Mots-clés : Covid-19, Mali, tourisme, néocolonialisme, rumeurs

Keywords : Covid-19, Mali, tourism, neo-colonialism, rumors

\section{AUTEUR}

\section{ANNE DOQUET}

Chargée de recherche à l'Institut de recherche pour le développement (IRD), Institut des mondes Africains (IMAF)

anne.doquet[at]ird.fr 